\title{
Fasting Plasma Levels of Glucose, Acetoacetate, $D$ - $\beta$-Hydroxybutyrate, Glycerol, and Lactate in the Baboon Infant: Correlation with Cerebral Uptake of Substrates and Oxygen
}

\author{
LYNNE L. LEVITSKY, ${ }^{(38)}$ DAVID E. FISHER, JOHN B. PATON, AND CLARENCE W. DELANNOY \\ Department of Pediatrics and Laboratory Animal Medicine, Michael Reese Hospital and Medical Center, Chicago, \\ Illinois, USA
}

\begin{abstract}
Summary
The energy-rich substrates available to the fasting stressed baboon neonate and infant are quantitatively similar to the metabolic fuels presented to the stressed low birth weight human newborn. Within a few hours after birth, fasting arterial plasma glucose levels in the baboon neonate approximate those of 4-6week-old baboon infants after a 20-hr fast. Lactate levels are high and comparable for both age groups. In contrast, $\beta$-hydroxybutyrate is quite low in the immediate neonatal period, but rises to significantly higher levels $(P<0.001)$ after a fast at 4-6 weeks. In addition, glycerol levels are higher $(P<0.02)$ in the fasted older infant compared with the fasting neonate.

Computation of mean cerebral blood arteriovenous dififerences and oxygen equivalents for animals studied in the first 50 hr of life demonstrates that glucose uptake can account for $50 \%$ or less of cerebral oxygen consumption in the newborn period. In confirmation, the respiratory quotient in these animals is $0.52 \pm 0.06$.

Cerebral oxygen consumption in the immediate neonate is greater than can be explained by utilization of glucose and the small quantities of acetoacetate and $\beta$-hydroxybutyrate available at this time. At birth, cerebral uptake of lactate is noted, but this phenomenon is not observed at 6 and 12 weeks of age.
\end{abstract}

\section{Speculation}

The baboon model for dynamic studies of neonatal energy metabolism may permit investigations of greater clinical relevance than those in lower mammalian model systems. It is suggested that lactate may be a significant cerebral energy source in the immediate neonatal period.

Physiologic adaptation of the newly born infant to extrauterine life has been the subject of intensive investigation. Homeostatic adjustments in energy metabolism which occur postnatally have been of particular concern because of the clinical significance of disordered energy metabolism in the human neonate. Studies of these neonatal adaptations have been carried out in a number of mammalian species including the rat, lamb, and pig $(4,12,29,32)$. Conclusions drawn from these studies have on occasion been applied to the human newborn.

In an attempt to develop a clinically relevant model for investigation of metabolic alterations in the neonate, we have turned to a subhuman primate, the baboon. This animal has a gestational period of $184 \pm 10$ days. At birth, it resembles the smallfor-gestational age human infant in terms of responses to fasting and diminished body fat. We have examined fasting arterial plasma levels of energy substrates and have compared these with data obtained in the stressed low birth weight human neonate Further, as an initial step in defining the usefulness of this preparation, studies of cerebral uptake of energy substrates have been carried out.

\section{METHODS}

Twenty baboon infants were studied. Infants were the products of timed matings. Fourteen baboon neonates were delivered by cesarean section at term after a gestation of $172 \pm 1$ days, and six were delivered spontaneously after a gestation of $175 \pm 4$ days. The mean birth weight of animals delivered by cesarean section was $824 \pm 25 \mathrm{~g}$, and of spontaneous deliveries, $825 \pm 35$ g. Blood samples were obtained from these animals as outlined in Table 1. In seven animals, 1-2-ml arterial blood samples were obtained from a catheter placed in the left ventricular outflow tract at 4-6, 24, and/or 48-50 hr of life. A solution of $5 \%$ dextrose in $0.2 \%$ saline was infused intravenously at a rate of 60 $\mathrm{cc} / \mathrm{kg} /$ day after the initial arterial blood samples. Six other animals had repeated arterial blood samples obtained at 20-min intervals at 4-6 hr of life. Seven baboon neonates were studied in a similar manner after an overnight fast at 4-6 weeks of life, and one neonate was studied at 12 weeks. Two of the animals investigated at 4-6 weeks had been delivered by cesarean section and previously studied at birth. The others were spontaneous vaginal deliveries. The mean body weight at 4-6 weeks was $1,061 \pm 75 \mathrm{~g}$, and body weight of the 12-week neonate was $1,160 \mathrm{~g}$. Animals were maintained in infant incubators and fed commercial infant formula until the time of study. In eeight neonates studied by blood sampling in the first $48 \mathrm{hr}$ of life and two infants studied similarly at 6 and 12 weeks of age, catheters were placed in the superior sagittal sinus as well as in the left ventricular outflow tract. Simultaneous 1-2-ml arterial and venous blood samples were drawn in these animals. Blood was replaced volume for volume with placental or maternal blood in all infants. Animals were studied initially $2-4 \mathrm{hr}$ after catheter placement under local anesthesia. They were maintained under a radiant warmer during procedures, and restrained but not sedated.

Plasma samples were analyzed for glucose using a glucose oxidase oxygen electrode technique (Beckman) and for glycerol (14), lactate (16), acetoacetate, and D- $\beta$-hydroxybutyrate (23) using enzymatic fluorometric methods. Samples were analyzed immediately or frozen at $\mathbf{- 7 0}$ until analysis. All analyses were performed in triplicate. However, not all substrate analyses were performed on each specimen. Blood arteriovenous differences were computed from plasma differences using a correction for hematocrit. Blood gas determinations were performed using Radiometer electrodes and meter PHM 71. The $\mathrm{pH}$ and $\mathrm{PO}_{2}$ 
were measured directly; $\mathrm{PCO}_{2}$ was determined by the equilibration method. Oxygen content was calculated from a previously. developed nomogram (22). Using a radioactive microsphere technique (21), cardiac output and cerebral cortex blood flows were determined in five neonates in the first $48 \mathrm{hr}$ of life and in two infants at 6 and 12 weeks, respectively. These were used to compute cerebral glucose and oxygen consumption.

Comparisons between arterial plasma levels at different ages were evaluated using the two tailed Student $t$-test. Validation of cerebral arteriovenous uptake of substrate during single sampling was performed using the nonparametric Wilcoxon rank test. Cerebral cortex arteriovenous differences of substrates were compared with arterial levels by linear regression analysis using a program of the Wang 500 computer.

\section{MATERIALS}

Baboon infants were obtained from the University of Illinois Primate Colony (Chicago, Ill.). Enzymes for substrate assays were obtained from Boehringer-Mannheim, New York, N. Y. (glycerokinase, glycerophosphate dehydrogenase) and Sigma, St. Louis, Mo. (lactic dehydrogenase, D- $\beta$-hydroxybutyric dehydrogenase). Reagents used to construct standard curves were purchased from Sigma (lactic acid, DL- $\beta$-hydroxybutyrate), Sargent-Welch, Chicago, Ill. (glycerol), and J. D. Baker, Phillipsburg, N. J. (ethylacetoacetate). Lithium acetoacetate was prepared from ethylacetoacetate (8). NADH and

Table 1. Timetable of blood sampling

\begin{tabular}{lccccc}
\hline \multicolumn{1}{r}{ Animal } & $4-6 \mathrm{hr}$ & $24 \mathrm{hr}$ & $48 \mathrm{hr}$ & 6 weeks & 12 weeks \\
\hline $1-4(\mathrm{C} / \mathrm{S})$ & + & + & + & & \\
$5-6(\mathrm{C} / \mathrm{S})$ & & + & + & & \\
$7(\mathrm{C} / \mathrm{S})$ & & & + & & \\
$8(\mathrm{C} / \mathrm{S})$ & $* *$ & & & & \\
$9-12(\mathrm{C} / \mathrm{S})$ & $*$ & & & $*$ & \\
$13,14(\mathrm{C} / \mathrm{S})$ & $*$ & & & $* *$ & \\
15 (spont.) & & & & $* *$ \\
$16-19$ (spont.) & & & & $*$ & \\
20 (spont.) & & & & & $*$ \\
\hline
\end{tabular}

${ }^{1} \mathrm{C} / \mathrm{S}$ : cesarean section; spont.: spontaneous delivery; +: single arterial sampling with cerebral arteriovenous differences, ${ }^{*}$ : multiple arterial sampling; **: multiple arterial sampling with cerebral arteriovenous differences.
NAD were purchased from Sigma. Fluorometric analyses were performed on an Aminco-Bowman SPF-125 spectrophotofluorometer.

\section{RESULTS}

\section{FASTING ARTERIAL PLASMA SUBSTRATE LEVELS}

Within a few hours after birth, arterial plasma glucose levels approximated those of 4-6-week-old infants after a 20-hr fast (Table 2). Lactate levels were high and comparable for both age groups. In contrast, $\beta$-hydroxybutyrate was quite low in the immediate neonatal period, but rose to significantly higher levels $(P<0.001)$ after a fast at $4-6$ weeks. In addition, glycerol levels were higher $(P<0.02)$ in the fasted older infant compared with the fasting neonate.

In order to prevent lethal hypoglycemia and maintain some of these animals for study over a 48-hr period, $5 \%$ dextrose in $0.2 \%$ saline was infused intravenously as previously described. In spite of low glucose levels, after $48 \mathrm{hr}$ of this modified fast, arterial plasma $\beta$-hydroxybutyrate was not as elevated as in 4-6week-old infants fasted for a shorter period (Table 3).

CEREBRAL ARTERIOVENOUS DIFFERENCES OF ENERGY SUBSTRATES AND OXYGEN, OXYGEN EQUIVALENTS, AND RESPIRATORY QUOTIENT (R. Q.)

Mean computed cerebral blood arteriovenous differences and oxygen equivalents for animals studied in the first $50 \mathrm{hr}$ of life are delineated in Table 4 . Mean cerebral oxygen uptake was $6.15 \pm 0.4 \mathrm{mM} /$ liter and the mean $R$. Q. was $0.52 \pm 0.06$. In Figure 1, cerebral plasma arteriovenous differences for $\beta$-hydroxybutyrate, acetoacetate, glycerol, and lactate are compared with the arterial levels for these substrates over the first $50 \mathrm{hr}$ of life. In contrast to glycerol and to glucose, ketone body and lactate uptake is directly related to arterial plasma concentration.

As these data are based upon single simultaneous samplings over a $50-\mathrm{hr}$ period, it is of interest to look at animals studied by repeated blood sampling at birth and at 6 or 12 weeks in the same manner (Table 5). Although cerebral uptake of lactate is noted at birth, the phenomenon is not observed at 6 and 12 weeks of age. Uptake of glycerol is also not observed in these animals.

It is evident that glucose uptake can account for $50 \%$ or less of oxygen consumption in the newborn period. However, the other

Table 2. Plasma arterial levels of energy substrates in millimolar concentration per liter in fasting baboon infants

\begin{tabular}{|c|c|c|c|c|c|c|c|c|c|c|c|}
\hline \multirow[b]{2}{*}{ Animal } & \multicolumn{5}{|c|}{$4-6 \mathrm{hr}$ after birth } & \multirow[b]{2}{*}{ Animal } & \multicolumn{5}{|c|}{6 weeks after birth (20-hr fast) } \\
\hline & Glucose & $\beta-\mathrm{OHB}^{\prime}$ & $A C-A C^{2}$ & Lactate & Glycerol & & Glucose & $\beta$-ОНВ & AC-AC & Lactate & Glycerol \\
\hline 1 & $2.00^{3}$ & $0.086^{3}$ & $0.110^{3}$ & $2.32^{3}$ & $0.329^{3}$ & 15 & $5.10^{4}$ & 3.67 & 2.00 & 1.37 & 0.303 \\
\hline 2 & $1.79^{3}$ & $0.033^{3}$ & $0.127^{3}$ & $2.12^{3}$ & & 16 & 1.41 & 5.50 & & 1.46 & 0.512 \\
\hline 3 & $2.85^{3}$ & $0.012^{3}$ & $0.155^{3}$ & $0.89^{3}$ & $0.152^{3}$ & 17 & 2.51 & 6.15 & & 1.97 & 0.422 \\
\hline 4 & $3.65^{3}$ & & $0.130^{3}$ & $1.74^{3}$ & & 18 & 2.18 & 3.54 & & 1.66 & 0.380 \\
\hline 8 & 2.90 & 0.339 & & 2.75 & 0.199 & 19 & 2.96 & 3.76 & & 1.99 & 0.195 \\
\hline 9 & 3.08 & 0.109 & & 1.70 & 0.157 & & & & & & \\
\hline 10 & 2.92 & 0.140 & & 1.57 & 0.128 & & & & & & \\
\hline 11 & 2.47 & 0.114 & & 3.35 & 0.114 & & & & & & \\
\hline 12 & 3.03 & 0.113 & & 2.82 & 0.247 & & & & & & \\
\hline 13 & 4.02 & 0.120 & & 3.86 & 0.150 & 13 & 3.64 & 4.04 & & 2.92 & 0.163 \\
\hline 14 & 3.14 & $0.095^{3}$ & & 2.48 & 0.144 & 14 & 2.13 & & & 2.14 & \\
\hline No. of animals & 11 & 10 & 4 & 11 & 9 & & 7 & 6 & 1 & 7 & 6 \\
\hline Mean & 2.90 & 0.116 & 0.130 & 2.33 & 0.180 & & 2.85 & 4.44 & 2.00 & 1.93 & 0.326 \\
\hline SE & 0.19 & 0.028 & 0.009 & 0.26 & 0.023 & & 0.46 & 0.45 & & 0.20 & 0.047 \\
\hline
\end{tabular}

' $\beta$-Hydroxybutyrate.

${ }^{2}$ Acetoacetate.

${ }^{3}$ Single blood sample.

"Animal 15 was unusually resistant to fasting, but did not display a "stress" hyperglycemia, as evidenced by low arterial lactate levels. 
substrates which contribute to oxygen consumption may vary with age.

\section{CEREBRAL CORTEX BLOOD FLOW, OXYGEN CONSUMPTION, AND UPTAKE OF ENERGY SUBSTRATES}

Cerebral cortex blood flow was determined in four animals studied by single blood sampling over $48 \mathrm{hr}$ and in the three animals studied repetitively at birth and at 6 or 12 weeks of life (Table 6). With the small amount of information available, it is not possible to reach conclusions regarding age-related changes in blood flow per $\mathrm{g}$ cortical tissue. Oxygen consumption and glucose uptake per $g$ tissue were comparable in the 6- and 12week-old infants to that in the four animals studied over the first 2 days of life. However, the one animal studied repetitively at birth had a lower cerebral cortex blood flow and correspondingly lower oxygen consumption and glucose uptake. Inspection of arterial oxygen content suggests that this animal was relatively hypoxic during study. Nonetheless, glucose to oxygen ratios

Table 3. Plasma arterial levels of energy substrates in millimolar concentration per liter (mean $\pm S E$ ) in fasting baboon neonates

sustained by infusion of $5 \%$ dextrose $-0.2 \%$ saline at rate of $60 \mathrm{cc} / \mathrm{kg} / 24 \mathrm{hr}$

\begin{tabular}{|c|c|c|}
\hline \multirow[b]{2}{*}{ Substrate } & \multicolumn{2}{|c|}{ Time } \\
\hline & $24 \mathrm{hr}$ & $48 \mathrm{hr}$ \\
\hline Glucose & $3.14 \pm .29(6)^{\prime}$ & $1.92 \pm 0.19(5)$ \\
\hline Lactate & $1.24 \pm 0.30(6)$ & $0.97 \pm 0.20(7)$ \\
\hline Glycerol & $0.265 \pm 0.030(4)$ & $0.227 \pm 0.036$ \\
\hline$\beta$-Hydroxybutyrate & $0.442 \pm 0.124(5)$ & $1.23 \pm 0.60(6)$ \\
\hline Acetoacetate & $0.289 \pm 0.054$ & $0.775 \pm 0.317(7)$ \\
\hline
\end{tabular}

' Number of observations. ranged only from 0.28 to 0.44 for these animals, suggesting that the relationship of glucose uptake to oxygen consumption was unchanged by age.

\section{DISCUSSION}

The metabolic response of the neonatal baboon to fasting and stress is similar to the response of the stressed low birth weight human neonate. In general, these primate newborns rapidly become hypoglycemic and display elevations of arterial plasma lactate comparable to those previously reported in the underweight stressed human infant (31). In addition, fasting plasma levels of ketone bodies and glycerol are low at birth, and are significantly higher after a fast in older infants.

It is apparent that the energy-rich substrates available to the stressed baboon neonate and infant are quantitatively similar to the metabolic fuels presented to many stressed human newborns. This model therefore lends itself to clinically relevant studies of energy substrate utilization and production by specific

Table 4. Oxygen utilizution equivalents computed from measured cerebral plasma arteriovenous differences for selected substrates in millimolar concentration per liter (mean $\pm S E$ )

\begin{tabular}{lccc}
\hline \multicolumn{1}{c}{ Substrate } & $\begin{array}{c}\text { Mean plasma } \\
\text { arteriovenous } \\
\text { difference }\end{array}$ & $\begin{array}{c}\text { Mean calcu- } \\
\text { lated blood ar- } \\
\text { teriovenous } \\
\text { difference }\end{array}$ & $\begin{array}{c}\text { Calculated } \\
\mathrm{O}_{2} \\
\text { equivalent }\end{array}$ \\
\hline Glucose & $0.595 \pm 0.039$ & $0.336 \pm 0.023$ & $2.016 \pm 0.139$ \\
Acetoacetate & $0.060 \pm 0.026$ & $0.034 \pm 0.014$ & $0.136 \pm 0.056$ \\
$\beta$-Hydroxybutyrate & $0.165 \pm 0.040$ & $0.105 \pm 0.030$ & $0.472 \pm 0.133$ \\
Lactate & $0.173 \pm 0.041$ & $0.095 \pm 0.022$ & $0.285 \pm 0.066$ \\
Glycerol & $0.024 \pm 0.010$ & $0.014 \pm 0.006$ & $0.049 \pm 0.021$ \\
\hline
\end{tabular}
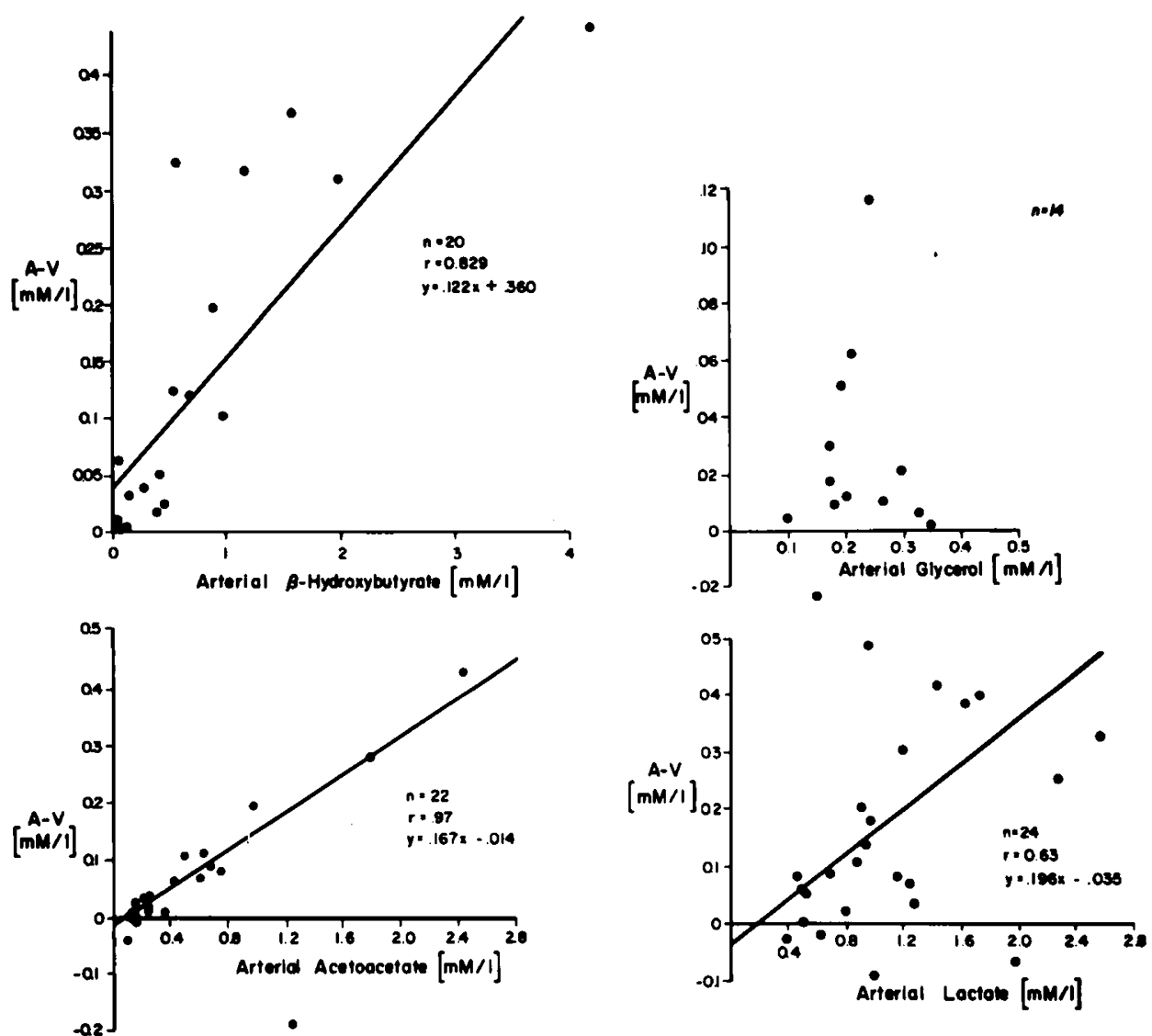

Fig. 1. Cerebral uptake of $\beta$-hydroxybutyrate, acetoacetate, glycerol, and lactate in the baboon nenonate. Plasma arteriovenous $(A-V)$ differences of these substrates are compared with plasma arterial levels. 
Table 5. Substrate oxygen equivalents, respiratory quotients (R.Q.), and cerebral plasma arteriovenous differences for substrates and oxygen in millimolar concentration per liter (mean $\pm S E$ ) in baboons studied at birth, 6 or 12 weeks of age by repetitive sampling

\begin{tabular}{|c|c|c|c|c|c|c|c|c|c|}
\hline & Glucose & $\begin{array}{l}\beta \text {-hydrox- } \\
\text { ybutyrate }\end{array}$ & $\begin{array}{c}\text { Acetoace- } \\
\text { tate }\end{array}$ & Lactate & Glycerol & Oxygen & R.Q. & $\begin{array}{c}\text { Glucose } \\
\mathrm{O}_{2} \\
\text { equiva- } \\
\text { lent' }\end{array}$ & $\begin{array}{c}\text { Total } \\
\text { measured } \\
\mathrm{O}_{2} \text { equiv- } \\
\text { alent }^{2}\end{array}$ \\
\hline \multicolumn{10}{|l|}{ Birth (animal 8) } \\
\hline \multirow[t]{2}{*}{ Plasma arterial substrate level } & 2.9 & 0.339 & & 2.75 & 0.199 & 5.9 & & & \\
\hline & \pm 0.20 & \pm 0.095 & & \pm 0.15 & \pm 0.061 & \pm 0.5 & & & \\
\hline \multirow[t]{2}{*}{ Plasma arteriovenous difference } & 0.4 & 0.028 & & 0.30 & N.S. & 2.7 & 0.60 & 1.4 & 2.0 \\
\hline & \pm 0.1 & \pm 0.007 & & \pm 0.03 & & \pm 0.5 & \pm 0.14 & \pm 0.4 & \pm 0.5 \\
\hline No. of samples & 5 & 5 & & 5 & 5 & 3 & & & \\
\hline \multicolumn{10}{|l|}{ At 6 weeks (animal 15) } \\
\hline \multirow[t]{2}{*}{ Plasma arterial substrate level } & 5.1 & 3.67 & 2.00 & 1.37 & 0.303 & 9.5 & & & \\
\hline & \pm 0.54 & \pm 0.21 & \pm 0.13 & \pm 0.20 & \pm 0.032 & \pm 0.4 & & & \\
\hline \multirow[t]{2}{*}{ Plasma arteriovenous difference } & 0.8 & 0.35 & 0.51 & -0.20 & 0.024 & 7.1 & 0.36 & 2.9 & 4.2 \\
\hline & \pm 0.2 & \pm 0.07 & \pm 0.08 & \pm 0.11 & \pm 0.006 & \pm 0.8 & \pm 0.05 & \pm 0.7 & \pm 1.3 \\
\hline \multirow{2}{*}{\multicolumn{10}{|c|}{$\begin{array}{l}\text { No. of samples } \\
\text { At } 12 \text { weeks (animal 20) }\end{array}$}} \\
\hline & & & & & & & & & \\
\hline \multirow[t]{2}{*}{ Plasma arterial substrate level } & 2.1 & 8.16 & 3.76 & 0.95 & 0.400 & 8.2 & & & \\
\hline & \pm 0.06 & \pm 0.23 & \pm 0.09 & \pm 0.09 & \pm 0.014 & \pm 0.4 & & & \\
\hline \multirow[t]{2}{*}{ Plasma arteriovenous difference } & 0.3 & 0.65 & 0.28 & -0.15 & -0.052 & 3.9 & 0.37 & 1.2 & 3.5 \\
\hline & \pm 0.05 & \pm 0.22 & \pm 0.07 & \pm 0.04 & \pm 0.012 & \pm 0.9 & \pm 0.12 & \pm 0.2 & \pm 0.6 \\
\hline No. of samples & 9 & 9 & 9 & 9 & 9 & 4 & & & \\
\hline
\end{tabular}

${ }^{1}$ Blood values computed from hematocrit.

${ }^{2}$ Calculated from $\mathrm{O}_{2}$ equivalent derived from glucose, ketones, and lactate.

Table 6. Cerebral cortex blood flow, oxygen consumption, and glucose uptake in baboon infants

\begin{tabular}{|c|c|c|c|c|c|}
\hline & $\begin{array}{c}\text { Blood flow, } \mathrm{ml} / \\
\min \end{array}$ & $\begin{array}{c}\text { Blood flow, } \mathrm{ml} / \\
\mathrm{min} / \mathrm{g}\end{array}$ & $\begin{array}{c}\text { Calculted } \mathrm{O}_{2} \text { uptake, } \\
\mu \mathrm{M} / \mathrm{min} / \mathrm{g}\end{array}$ & $\begin{array}{l}\text { Calculated glu- } \\
\text { cose uptake, } \\
\mu \mathrm{M} / \mathrm{min} / \mathrm{g}\end{array}$ & $\begin{array}{c}\text { Glucose } / \mathrm{O}_{2} \\
\text { ratio' }\end{array}$ \\
\hline Birth-48 $\mathrm{hr}^{2}$ (animals $\left.1,2,3,5\right)$ & $12.4 \pm 3.0$ & $0.17 \pm 0.03$ & 1.14 & 0.06 & 0.31 \\
\hline Birth (animal 8) & $7.6 \pm 1.0(2)$ & $0.10 \pm 0.01(2)$ & 0.27 & 0.02 & 0.44 \\
\hline 6 weeks (animal 15) & $15.5 \pm 0.2(2)$ & $0.18 \pm 0.00(2)$ & 1.28 & 0.09 & 0.42 \\
\hline 12 weeks (animal 20 ) & $37.6 \pm 7.3(2)$ & $0.33 \pm 0.07(2)$ & 1.29 & 0.06 & 0.28 \\
\hline
\end{tabular}

' (Glucose uptake $\times 6) /\left(\mathrm{O}_{2}\right.$ uptake).

${ }^{2}$ Seven blood flow determinations in four animals; glucose and oxygen were determined immediately before blood flow studies. The arteriovenous difference for oxygen was $6.7 \pm 0.7 \mathrm{mM} / \mathrm{L}$ (mean $\pm \mathrm{SE}$ ) in these animals. The range of blood flows was $0.084-0.365 \mathrm{ml} / \mathrm{min} / \mathrm{g}$.

organ systems. As an initial demonstration of the utility of such a model, we have examined cerebral oxygen uptake as well as quantitative energy substrate uptake and release.

The normal human adult brain utilizes approximately 1.56 $\mu \mathrm{M}$ oxygen $/ \mathrm{min} / \mathrm{g}$ tissue (30). If we exclude one animal (8), which was relatively hypoxic when studied, calculated oxygen uptakes in our baboon neonates are approximately two-thirds of this value. Earlier studies in rodents suggested that cerebral oxygen uptake increases markedly with increasing cerebral maturity (11). However, there is a paucity of data in primate species.

In agreement with our findings in the baboon, Settergren et al. (26) recently reported a mean cerebral oxygen consumption of $1.04 \mu \mathrm{m} / \mathrm{min} / \mathrm{g}$ brain tissue in nine anesthetized human infants. It is likely, then, that maturational changes in cerebral oxygen consumption are much less prominent in primates than in some other mammalian species.

In vitro, brain tissue can use a wide variety of substrates in addition to glucose, including ketone bodies (6), lactate, pyruvate, acetate, and amino acids (29). Furthermore all of the normal enzymatic pathways for oxidative metabolism are present in brain tissue preparations (1). In vivo studies in lower mammalian species have demonstrated that ketone bodies (5), glycerol (25), and free fatty acids (7) may be alternative cerebral fuel sources. In 1967, Owen et al. (19) established that cerebral uptake of ketone bodies was considerable in ketotic man and could play a significant role in human cerebral energy metabo- lism. Since then, reports of uptake of ketones by the brains of infants (13) and of children undergoing surgical anesthesia (24), utilization of ${ }^{14} \mathrm{C}$-labeled $\beta$-hydroxybutryate by the isolated brain of the human fetus (2), and identification of the enzymes of ketone body utilization in human brain tissue (20) have established that ketones can be an important alternate source of energy for human cerebral metabolism.

Cerebral uptake of ketone bodies has previously been shown to be directly correlated with the arterial level of these compounds. We have documented the relationship between arterial levels of ketone bodies and cerebral uptake in the baboon neonate. However, we have also demonstrated that cerebral oxygen consumption in the neonate is greater than can be explained by utilization of glucose and the small quantities of acetoacetate and $\beta$-hydroxybutyrate available at this time. Therefore, it was of interest to discover that we could demonstrate cerebral uptake of lactate in neonatal baboons studied by arteriovenous sampling, although not in older infant baboons. This is in marked contrast to most previous studies in mammalian species, which have reported cerebral production of lactate.

The role of lactate in cerebral energy metabolism of the human neonate has been a subject of speculation for some years $(3,27)$, but previous attempts to document cerebral lactate uptake in the fetal and neonatal period have been largely unsuccessful. In particular, the brains of hypoglycemic fetal sheep apparently do not take up lactate $(12,17)$. However, cerebral metabolism in the sheep seems to be different from that in other 
mammals studied in that significant cerebral uptake or utilization of ketone bodies is not readily demonstrable in either ketotic adult (15) or fetal sheep (12). We cannot definitively state that lactate is an important cerebral fuel in the baboon newborn. Nevertheless, we have demonstrated uptake of this substrate in the immediate neonatal period. Inasmuch as lactate utilization in older individuals must be limited by cerebral permeability and membrane transport mechanisms rather than by absence of enzymatic oxidative pathways, it is possible that the immature stressed primate brain may indeed utilize lactate as an energy substrate.

Lactate has been demonstrated to cross into the brain relatively inefficiently, perhaps by a process of facilitated diffusion (18). In the immature rat, anoxia recently has been shown to enhance cerebral uptake of lactate (33). Utilization of lactate by the mammalian brain has been amply demonstrated $(30)$, as has production of this substrate as a consequence of glucose utilization (9). In vitro, increased levels of ketone bodies apparently lead to increased cerebral production of lactate (25). Therefore, net cerebral uptake or release of lactate may be dependent upon a balance between lactate utilization and production. One might speculate that in the presence of low concentrations of cerebral ketone bodies and an immature blood-brain barrier, lactate uptake could exceed production. Conversely, in older infants with higher cerebral ketone levels, lactate production might be greater than uptake and utilization.

When one looks at the cerebral cortex arteriovenous difference for oxygen in our baboon infants and at the theoretic oxygen equivalents generated by glucose uptake in all animals studied, it is apparent that less than $50 \%$ of oxygen consumption can be explained by glucose utilization. We cannot completely account for cerebral oxygen consumption by considering only estimates of glucose, ketone body, and lactate uptake. Therefore, it is probable that substrates other than those measured are important in cerebral energy metabolism. The search for alternative cerebral energy sources should include evaluation of the role of amino acids and free fatty acids, which may be elevated in the fasting stressed neonate $(10,31)$.

\section{CONCLUSION}

The quantitative similarity of energy substrates available to the baboon and stressed low birth weight human neonate is detailed. Cerebral cortex uptake of glucose, lactate, and ketone bodies is described.

\section{REFERENCES AND NOTES}

1. Abood, L. G., Gerard, R. W., Banks, J., and Tschirgi, R. D.: Substrate and enzyme distribution in cells and cell fractions of the nervous system. Amer. J. Physiol., 168: 728 (1952).

2. Adam, P. A. J., Răihă, N., Rahiala, E.-L., and Kekomäki, M.: Oxidation of glucose and D- $\beta-O H$-butyrate by the early human fetal brain. Acta Paediat. Scand., 64: 17 (1975).

3. Beard, A., Cornblath, M., Gentz, J., Kellum, M., Persson, B., Zetterstrom, R., and Haworth, J. C.: Neonatal hypoglycemia: A discussion. J. Pediat. 79: 314 (1971).

4. Cake, M. H., Yeung, D., and Oliver, I. T.: The control of postnatal hypoglycemia. Biol. Neonate, 18: 183 (1971).

5. Daniel, P. M., Love, E. R., Moorehouse, S. R., Pratt, O. E., and Wilson, P.: Factors influencing utilisation of ketone-bodies by brain in normal rats and rats with ketoacidosis. Lancet, 2: 637 (1971).

6. Drahota, Z., Hahn, P., Mourek, J., and Trojanová, M.: The effect of acetoacetate on oxygen consumption of brain slices from infant and adult rats. Physiol. Bohemoslov., 14: 134 (1965).

7. Geiger, A.: Correlation of brain metabolism and function by the use of a brain perfusion method in situ. Physiol. Rev., 38: 1 (1958).

8. Hall, L. M.: Preparation of crystalline lithium acetoacetate. Anal. Biochern. 3: 75 (1962)

9. Hawkins, R. A., Williamson, D. H., and Krebs, H. A.: Ketone-body utiliza- tion by adult and suckling rat brain in vivo. Biochem. J., 122: 13 (1971).

10. Haymond, M. W., Karl, I. E., and Pagliara, A. S.: Increased gluconeogenic substrates in the small-for-gestational-age infant. New Engl. J. Med., 291: 322 (1974)

11. Jilek, L., Travnickova, E., and Trojan, S.: Characteristic metabolic and functional responses to oxygen deficiency in the central nervous system. In: U. Stave: Physiology of the Perinatal Period, p. 987 (Appleton-CenturyCrofts, New York, 1970).

12. Jones, M. D., Burd, L. I., Makowski, E. I., Meschia, G., and Battaglia, F. C.: Cerebral metabolism in sheep: A comparative study of the adult, the lamb, and the fetus. Amer. J. Physiol., 229: 235 (1975).

13. Kraus, H., Schlenker, S., and Schwedesky, D.: Developmental changes of cerebral ketone body utilization in human infants. Hoppe-Seyler's Z. Physiol. Chem., 355: 164 (1974).

14. Laurell, S., and Tibbling, G.: An enzymatic fluorometric micromethod for the determination of glycerol. Clin. Chim. Acta, 13: 317 (1966).

15. Lindsay, D. B., and Setchell, B. P.: Cannulation of the sagittal sinus for the determination of cerebral ketone body metabolism in sheep. J. Physiol., 226: 51 (1972).

16. Loomis, M. E.: An enzymatic fluorometric method for the determination of lactic acid in serum. J. Lab. Clin. Med., 57: 966 (1961).

17. Mann, L. I., Duchin, S., Halverstram, J., Mastrantonio, J., Weiss, R., and Schulman, J.: The effect of hypoglycemia on fetal brain function and metabolism. Amer. J. Obstet. Gynecol., 117: 45 (1973).

18. Oldendorf, W. H.: Blood brain barrier permeability to lactate. Eur. Neurol., 6: $49(1971 / 72)$.

19. Owen, O. E., Morgan, A. P., Kemp, H. G., Sullivan, J. M., Herrera, M. G., and Cahill, G. F.: Brain metabolism during fasting. J. Clin. Invest., 46: 1589 (1967).

20. Page, M. A., and Williamson, D. H.: Enzymes of ketone-body utilisation in human brain. Lancet, 2: 66 (1971).

21. Paton, J. B., Fisher, D. E., Saba, T. M., and Behrman, R. E.: Measurement of liver blood flow in the infant monkey: A comparison of methods. Biol. Neonate, 23: 1 (1973)

22. Paton, J. B., Peterson, E., Fisher, D. E., and Behrman, R. E.: Oxygen dissociation curves of fetal and adult baboons. Resp. Physiol., 12: 283 (1971).

23. Persson, B.: Determination of plasma acetoacetate and $D-\beta$-hydroxybutyrate in newborn infants by an enzymatic fluorometric micro-method. Scand. J. Clin. Lab. Invest., 25: 9 (1969).

24. Persson, B., Settergren, G., and Dahlquist, G.: Cerebral arterio-venous difference of acetoacetate and D- $\beta$-hydroxybutyrate in children. Acta Paediat. Scand., 61: 273 (1972)

25. Rolleston, F. S., and Newsholme, E. A.: Effects of fatty acids, ketone bodies, lactate and pyruvate on glucose utilization by guinea-pig cerebral cortex slices. Biochem. J., 104: 519 (1967).

26. Settergren, G., Lindblad, B. S., and Persson, B.: Cerebral blood flow and exchange of oxygen, glucose, ketone bodies, lactate, pyruvate and amino acids in infants. Acta. Paediat. Scand., 65: 343 (1976).

27. Shelley, H.: General Discussion. In: Symposium on Development of Metabolism as Related to Nutrition. Biol. Neonate, 9: 172 (1965/66).

28. Sloviter, H. A., Shimkin, P., and Suhara, K.: Glycerol as a substrate for brain metabolism. Nature, 210: 1334 (1966).

29. Snell, K., and Walker, D. G.: Glucose metabolism in the newborn rat. Biochem. J., 134: 899 (1973).

30. Sokoloff, L.: Metabolism of ketone bodies by the brain. Annu. Rev. Med., 271 (1973).

31. Stave, U.: Metabolic effects in hypoxia neonatorum. In: U. Stave: Physiology of the Perinatal Period, p. 1043 (Appleton-Century-Crofts, New York, 1970).

32. Swiatek, K. R., Kipnis, D. M., Mason, G., Chao, K. L., and Cornblath, M.: Starvation hypoglycemia in newborn pigs. Amer. J. Physiol., 214: 400 (1968).

33. Vannucci, R. C., and Duffy, T. E.: Carbohydrate metabolism in fetal and neonatal rat brain during anoxia and recovery. Amer. J. Physiol., 230: 1269 (1976).

34. This research was presented in part at the Annual Meeting of the Society for Pediatric Research, 1973.

35. This work was carried out in part at the Abraham Lincoln School of Medicine, University of Illinois, and aided in part by United States Public Health Service General Research Support Grant RR5369 and United States Public Health Service Grant HD08608. We wish to acknowledge the excellent technical assistance of Ms. Jane Uehara, Ms. Lagrimas Munoz, and Ms. Audrey Paton.

36. Requests for reprints should be addressed to: L. L. Levitsky, M.D., Department of Pediatrics, Michael Reese Hospital and Medical Center, 29th St. and Ellis Ave. Chicago, Ill. 60616 (USA)

37. Received for publication June 15,1976

38. Accepted for publication September 22, 1976 